archives-ouvertes

\title{
Interrater Variability in Pain Assessment of Long-term Care Residents with Dementia
}

\author{
Valérie Vitou, Marie-Christine Gély-Nargeot, Sophie Bayard
}

\section{To cite this version:}

Valérie Vitou, Marie-Christine Gély-Nargeot, Sophie Bayard. Interrater Variability in Pain Assessment of Long-term Care Residents with Dementia. Pain Management Nursing, WB Saunders, 2021, 10.1016/j.pmn.2020.12.002 . hal-03132470

HAL Id: hal-03132470

https: / hal-univ-montpellier3-paul-valery.archives-ouvertes.fr/ hal-03132470

Submitted on 5 Feb 2021

HAL is a multi-disciplinary open access archive for the deposit and dissemination of scientific research documents, whether they are published or not. The documents may come from teaching and research institutions in France or abroad, or from public or private research centers.
L'archive ouverte pluridisciplinaire HAL, est destinée au dépôt et à la diffusion de documents scientifiques de niveau recherche, publiés ou non, émanant des établissements d'enseignement et de recherche français ou étrangers, des laboratoires publics ou privés. 
Original Article

\title{
Interrater Variability in Pain Assessment of Long-term Care Residents with Dementia
}

\author{
Valérie Vitou, PhD ${ }^{*}{ }^{\dagger}$, Marie-Christine Gély-Nargeot, PhD *, Sophie Bayard, PhD * \\ * University Paul Valéry Montpellier 3, University Montpellier, Montpellier, France \\ ${ }^{\dagger}$ Fondation Partage et Vie, Montrouge, France
}

\section{A R T I C L E I N F O}

\section{Article history:}

Received 26 March 2020

Received in revised form

17 November 2020

Accepted 3 December 2020

\begin{abstract}
A B S T R A C T
Purpose: People with dementia are at great risk of their pain being undetected. In long-term care facilities, certified nursing assistants are on the front-line to detect whether a resident with dementia is experiencing pain, but research on certified nursing assistants' abilities to accurately assess pain are scarce. This study aims to examine certified nursing assistants' pain assessment skills using a simulated standardized video context.

Design: A cross-sectional study was conducted.

Methods: Fifty certified nursing assistants and 40 individuals with no professional experience in the field of care (controls) watched the same video of an older adult woman with dementia experiencing pain. Afterwards, they completed visual analog scales (pain intensity, affective distress), an observational pain assessment scale (Algoplus), and a set of questionnaires.

Results: In both groups, pain intensity assessment and empathic reaction scores showed important interrater variability. Moreover, certified nursing assistants and controls did not differ in detecting the presence of pain or assessing its intensity. But certified nursing assistants displayed lower empathic reactions and dispositions. Certified nursing assistants pain assessment scores decreased with experience and expertise.

Conclusions: The practice of pain assessment is challenging for certified nursing assistants in long-term care facilities. Their professional status does not prevent inter-personal inconsistency and tends to lower their empathic dispositions. Personal determinants may interfere with their assessment behaviors and must be considered to enhance pain management for residents with dementia.
\end{abstract}

Optimal pain management of long-term care facilities (LTC) residents with severe dementia is a great ethical and professional concern (Rostad et al., 2017). In France, a pivotal cohort study revealed that $72 \%$ of persons living in LTC are diagnosed with dementia, with more than two-third having severe impairments (Helmer et al., 2006). This population with significant cognitive disorders presents specific challenges to meet their care needs. Pain relief is one of these issues as persistent pain interferes on their day-to-day functioning, behavior, and psychological wellbeing (Corbett et al., 2014; Rajkumar et al., 2017; Rostad et al., 2017). It has been estimated that more than $50 \%$ of the residents with dementia

\footnotetext{
Address correspondence to Valérie Vitou, PhD, Laboratoire Epsylon, EA 4556 Université Paul Valéry Montpellier 3, Rue du Pr. Henri Serre, 34000 Montpellier, France.

E-mail address: vitou.valerie@orange.fr (V. Vitou).
}

experienced pain on a regular basis (Björk et al., 2016; Corbett et al., 2012). Nevertheless, compared with their cognitively intact counterparts, their pain is less often assessed (Reynolds et al., 2008; Tan et al., 2015) and they generally receive fewer analgesics (de Souto Barreto et al., 2013; Griffioen et al., 2017) despite being equally susceptible to painful conditions (Gagliese et al., 2017). This situation is problematic since successful pain management depends first on accurate pain assessment (Knopp-Sihota et al., 2019).

Assessing pain in people with moderate-to-severe dementia is often challenging. Indeed, when the illness reduces the person's competence to communicate it becomes difficult to rely on selfreport pain measures (Zwakhalen et al., 2018). Observational tools have been developed to address these difficulties, but their adequate use requires specific conditions (training, multidisciplinary team rating, regular reassessments) that are scarcely ever met in practice (Husebo et al., 2016). In LTC, certified nursing assistants (CNAs) are on the front line to acknowledge if a resident 
with dementia is experiencing pain or not (Cervo et al., 2007). However, these health professionals are not systematically trained in pain assessment (De Witt Jansen et al., 2017). CNAs have been shown to be effective in recognizing the presence of pain (Cervo et al., 2009; Fisher et al., 2002; Mentes et al., 2004) but their pain reports are judged less reliable than those of nurses (Chen et al., 2010). Several guidelines have been provided by health authorities and expert teams to improve pain management in older people (Hadjistavropoulos et al., 2014). However, these recommendations have difficulty being circulated and put into practice in LTC due to organizational constraints and lack of prioritization. Thus, pain assessment is not performed routinely by health care staff and they may not follow, or even be aware of, these pain management guidelines (Husebo et al., 2016; Zwakhalen et al., 2018).

Pain underestimation is a well-documented phenomenon among healthcare providers (Kappesser et al., 2006; Prkachin et al., 2007; Seers et al., 2018). Studies on physicians and nurses have shown that personal characteristics such as seniority (Prkachin et al., 2007), empathy (Goubert et al., 2009; Green et al., 2009), and burnout (Gleichgerrcht \& Decety, 2014) may influence the pain assessment ratings of the observers. But to the best of our knowledge, such studies have never focused on the CNAs in LTC population.

Given that background, the aims of this research were: (1) to characterize pain assessment behaviors of CNAs using validated observational tools in a standardized context; (2) to compare CNAs' pain assessment with those of individuals with no professional experience in the field of care (controls); and (3) to explore the impact of demographic, psychological, and socio-professional determinants on CNAs' pain assessment. Our hypotheses were that: (1) pain assessment scores will show significant interrater discrepancies in both groups; (2) CNAs' pain assessment scores will be lower than those of control participants; (3) CNAs' pain assessment scores will positively correlate with empathy trait scores and negatively correlate with experience and burnout.

We conducted a preliminary study to create and assess validity of standardized video material for pain assessment in an experimental context (study 1 ). Our specific objectives were subsequently addressed in a second study (study 2 ).

\section{Study 1: Design and Validation of the Video Material}

The aim of this study was to create and assess validity of video material which would be used subsequently in experimental research concerning pain assessment discrepancies in LTC health care staff. Therefore, we established the following specifications: the video clip should depict an older adult woman experiencing undefined moderate to severe pain and presenting no obvious clues about her cognitive status in order to be credibly associated with different labels or vignettes presenting specific clinical conditions. Four video clips were specially created for this purpose and a validation process was carried out to select the one that best met the different criteria.

\section{Material and Method}

\section{Participants}

The participants were a convenience sample of 56 adult females living in the community. The eligibility criteria were to be of working age (18-65 years old), and French speaking. People with medical or paramedical experience and psychology students were excluded from this sample. None of the participants had to have a history of neurological or psychiatric illness. They were enrolled by means of advertisements, personal contacts, and snowballing techniques. No compensation was provided.

\section{Material}

Four 15-second video clip trials were presented in random order to each participant. All the videos consisted of an older adult woman (actress) who was asked to mimic undefined pain while standing up from a deep chair with the help of another person. The face validity of the videos was verified by the researchers with the presence of several prototypical pain expressions (movement in the eye and mouth region, body position). Accuracy of the portrayals was judged by three healthcare professionals in the field of geriatrics who stated that the persons on the videos were actually experiencing pain.

\section{Measures}

In order to obtain both objective and subjective ratings of pain, two kind of tools were provided to the participants.

Algoplus: The Algoplus is a French validated observational scale for acute pain evaluation in older persons with communication disorders (Rat et al., 2011). It is now recommended for acute and chronic pain (Martin et al., 2016; Rat et al., 2014). It consists of five items (facial expression, look, complaints, body position, atypical behavior); each item is scored "yes" $=1$ or "no" $=0$. The existence of one behavior in each item is enough to tick "yes." Each item ticked "yes" gives one point, for a total maximal score of 5. A score greater than 2 or equal suggests the presence of pain and thereafter an initiation of analgesic treatment.

Pain intensity measure: the pain intensity visual analog scale (VAS) consisted of a horizontal line $100 \mathrm{~mm}$ in length, with semantic anchors at each end point (left $=$ no pain, right $=$ worst possible pain). On this VAS, participants were asked to evaluate the intensity of pain that they thought the person in the video clip was experiencing by marking on the line the point that they feel represents their perception. The VAS score was then determined by measuring in millimeters from the left-hand end of the line to the point that the participant marks (score range $=0$ to 100 ). The pain intensity VAS alone is not a valid tool for a proxy-report of pain in people with severe dementia in a clinical context, but some multidimensional pain assessment tools include a global pain intensity rating in addition to observational items (Snow et al., 2004; Villanueva et al., 2003). Pain intensity VAS is also often used in research to explore observer's pain assessment behaviors and bias (Prkachin et al., 2007; Seers et al., 2018).

All participants were also asked to estimate the age and cognitive status of the person on the video (with Alzheimer's disease, without Alzheimer's disease, don't know).

\section{Procedure}

The participants were encountered at the laboratory Epsylon (University Montpellier 3, France). After filling in the sociodemographic questionnaire, they were instructed to watch four short video clips presenting older adult women standing up from deep chairs, after which they would have to complete two scales to evaluate the pain expressed by these persons, and then answer a few questions about them. The video clips were then presented in full screen and at high sound level. The study was conducted in accordance with the Declaration of Helsinki (World Medical Association, 2013) and was approved by the competent ethics committee. After a complete description of the study, written informed consent was obtained. 
Results

The sample consisted of 56 female participants (age: $\mathrm{M}=35.61$, $S D=14.61$; educational attainment: $M=13,11, S D=4.58$ ) who evaluated the video clips. Out of the four presented video clips, the one which was evaluated to have best fulfilled the initial requirements in terms of pain presence/intensity, cognitive status, and age, was selected. The chosen video clip had the highest mode with the Algoplus (mode: 4; range: 1-5), the highest mean with the pain intensity VAS $(\mathrm{M}=73.2$; $\mathrm{SD}=16.14)$, and the highest occurrence of the "I don't know" answer at the cognitive status question (48\%). All the results of the selection process are presented in Table 1.

In conclusion, the selected video clip actually represents a painful situation experienced by an older adult woman with an uncertain cognitive status (with or without Alzheimer's disease) and is neutral enough to serve as material in experimental studies about the determinants of pain assessment discrepancies in LTC health care staff. This video clip is presented in online supplementary materials.

\section{Study 2: Interrater Variability in Pain Assessment}

\section{Material and Method}

\section{Participants}

To obtain a sufficient number of CNAs, five LTC facilities were approached, with the estimate that it would provide around 40 participants (8 per cell). Using a power calculation software G*Power (Faul et al., 2007), a power analysis for a compromise MANOVA, with repeated measures and within-between interaction, showed that with a medium effect size of $f(V)=0.50$ (according to Cohen, 1988), a $\beta / \alpha$ ratio $=1$ (assuming that both, $\alpha$ and $\beta$, are equally serious), and 2 groups, a sample size of 80 (40 CNAs and 40 controls) would lead to a power of $0.98, \alpha=0.02$ and a critical $\mathrm{F}(1,78)=5.67$. In the end, ninety female participants were enrolled for study 2: 50 CNAs and 40 controls. None of the participants took part in study 1 . For all participants, the eligibility criteria were to be of working age (from 18 to 65 years old), and French speaking. Women with history of neurological or psychiatric illness were excluded. Controls were adult females living in the community and had to have no medical or paramedical experience. Psychology students were also excluded. Controls were enrolled by means of advertisements, personal contacts, and snowballing techniques. All participants had to be willing to voluntarily participate in the study, no compensation was provided.

\section{Material}

\section{Sociodemographics}

Age, educational attainment, occupational status, and current or past chronic pain experiences were recorded. For the CNAs, duration of experience in geriatrics and in the present facility, prior pain assessment training during their education or professional course and prior use of the observational pain assessment tool used in this study (Algoplus) were also collected.

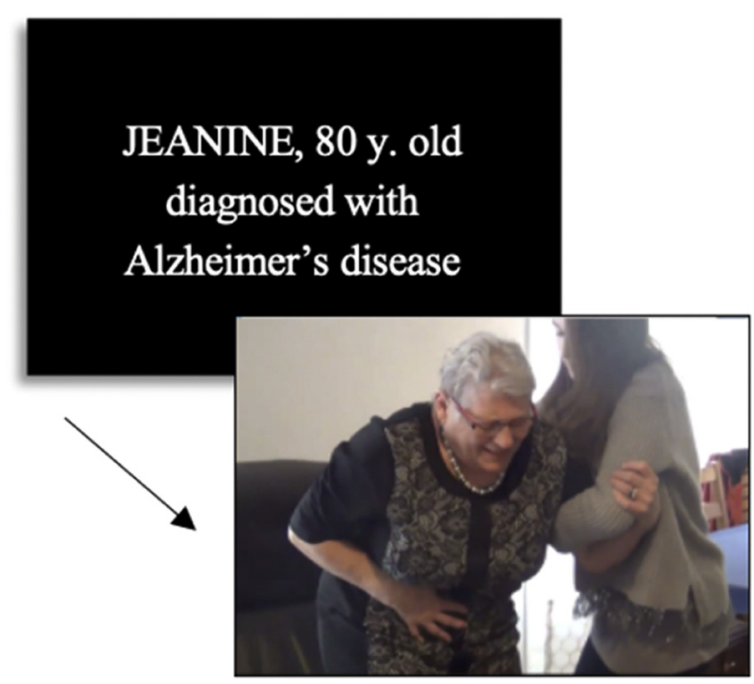

Figure 1. Video material selected in study 1 and used in study 2 .

\section{Video Clip}

The video clip selected in Study 1 was individually presented to all participants. Prior to this sequence, an information label appears in full screen for 5 seconds in white text on black background (see Fig. 1). The label gave the following information: Jeanine, 80 years old, diagnosed with Alzheimer's disease.

\section{Pain and Empathic Reaction Assessment}

In order to obtain both subjective and objective ratings, two kind of tools were provided to the participants.

Objective Pain Assessment tool: The Algoplus is a French validated observational scale for acute pain evaluation in older persons with communication disorders (Rat et al., 2011). It is now recommended for acute and chronic pain (Martin et al., 2016; Rat et al., 2014). It consists of five items (facial expression, look, complaints, body position, atypical behavior); each item is scored "yes" $=1$ or "no" $=0$. The existence of one behavior in each item is enough to tick "yes." Each item ticked "yes" gives one point, for a total maximal score of 5 . A score greater than 2 or equal suggests the presence of pain and thereafter an initiation of analgesic treatment. In a validation study, the Algoplus scale showed good psychometric properties (Rat et al., 2011). Its internal consistency was adequate for the total score according to the Kuder-Richardson-20 test (KR$20=0.712$ ). Spearman correlation coefficient between the Algoplus score and self-report pain intensity VAS was significant $(r=0.81$, $\mathrm{n}=44)$. Interrater reliability yielded an ICC of $0.812(\mathrm{n}=101)$. For patients with inability to communicate verbally, sensitivity and specificity were $87 \%$ and $80 \%$, respectively.

Subjective Assessment Measures: The VAS consisted of two horizontal lines $100 \mathrm{~mm}$ in length, with semantic anchors at each end point (score range $=0$ to 100 ). First, participants were asked to evaluate the intensity of pain that they thought the person in the video clip was experiencing (Pain intensity VAS: left = no pain, right $=$ worst possible pain). The pain intensity VAS alone is not a

Table 1

Study 1: Results of the Participants' Assessments $(N=56)$

\begin{tabular}{|c|c|c|c|c|}
\hline Video Clip \# & 1 & 2 & 3 & 4 \\
\hline Pain intensity VAS (0-100), Mean \pm SD & $61.86 \pm 19.07$ & $50.00 \pm 22.61$ & $73.21 \pm 16.14$ & $55.29 \pm 21.35$ \\
\hline Algoplus (0-5), Mode (min-max) & $3(1-5)$ & $3(0-4)$ & $4(1-5)$ & $3(0-5)$ \\
\hline Estimated age, Mean \pm SD & $75 \pm 6.06$ & $77 \pm 6.80$ & $74 \pm 7.26$ & $78 \pm 6.82$ \\
\hline Estimated cognitive status (\% I don't know) & $45 \%$ & $41 \%$ & $48 \%$ & $48 \%$ \\
\hline
\end{tabular}


valid tool for a proxy-report of pain in people with severe dementia in a clinical context, but some multidimensional pain assessment tools include a global pain intensity rating in addition to observational items (Snow et al., 2004; Villanueva et al., 2003). Pain intensity VAS is also often use in research to explore observer's pain assessment behaviors and bias (Prkachin et al., 2007; Seers et al., 2018). Then the participants were asked to rate their empathic reaction to pain of the other and more specifically the level of affective distress they felt watching the video (Affective distress VAS: left $=$ no affective distress, right $=$ extreme affective distress).

\section{Questionnaires}

The Interpersonal Reactivity Index-shortened French version (IRI) (Braun et al., 2015) is adapted from the 28-item initial scale (Davis, 1980). It offers a measure of trait empathy that comprises four subscales: fantasy scale (tendency to project oneself in the persona of a fictional character), perspective taking (predisposition to assume the psychological outlook of another person), empathic concern (ability to feel sympathy and compassion for another), and personal distress (the extent to which an individual feels anxiety as a result of witnessing another's emotional distress). The study of Braun (2015) validated the 4-dimension structure of the French short version and showed that all subscales had acceptable internal consistency considering the small number of items (fantasy scale: $\alpha=0.76$, perspective taking: $\alpha=0.62$, empathic concern: $\alpha=0.60$, personal distress: $\alpha=0.70$ ). According to the affective-cognitive structure of empathy (Davis, 1980), empathic concern and personal distress are considered two independent measures of emotional empathy focusing on the self- and other-oriented set of feelings elicited by an agent. Perspective taking, instead, is a measure of the cognitive aspect of empathy. The fantasy subscale was excluded, as it has been designed to tap on an ability that is not directly relevant in the care context (Gleichgerrcht \& Decety, 2014).

The Maslach Burnout Inventory (MBI) (Dion \& Tessier, 1994) is a 22-item self-report questionnaire that measures the frequency of perceived burnout among professionals, especially in the field of care. Participants are asked to rate using 7-point scales, how frequently they had a variety of feelings and experiences in their jobs $(0=$ never to $6=$ every day). The French version of the MBI evaluates three independent dimensions: emotional exhaustion $(\alpha=0.90)$, depersonalization ( $\alpha=0.64)$, and personal accomplishment $(\alpha=0.74)$. Burnout was defined by high scores on either emotional exhaustion $(\geq 30)$, and/or depersonalization $(\geq 12)$. The personal accomplishment dimension was not included in this study, given that this dimension is generally criticized and not used in the literature (Blanchard et al., 2010). The MBI was only completed by the CNAs group.

\section{Procedure}

CNAs were encountered in their workplace and controls came to the laboratory Epsylon (University Montpellier 3, France). Sociodemographics of the participants were collected during face-toface interviews conducted by five final year students in psychology at the University Paul Valéry Montpellier 3, France (supervised by SB \& VV). After this interview, participants were instructed that they would see a short video clip presenting an older adult woman standing up from a deep chair and that they will have to evaluate the pain expressed by the person, using VAS and the Algoplus scale. Participants of both groups were given the same standardized instructions concerning the use of the Algoplus scale (i.e., "the simple observation of a behavior mandates that it be checked as present, regardless of any etiological interpretation or the duration of its existence"). The video clip was then presented in full screen with a high sound level. Questionnaires were completed at the end of the session. The study was conducted in accordance with the Declaration of Helsinki (World Medical Association, 2013) and was approved by the competent ethics committee. After a complete description of the study, written informed consent was obtained from the participants.

\section{Statistical Analysis}

All statistical analyzes were performed with IBM SPSS software version 24.0, with a 2-tailed $\alpha$ level of $5 \%$. Data were tested for homogeneity of variance using the Levene test. No normal distribution was considered when absolute values for skewness and kurtosis were greater than 3 and 10, respectively (Weston \& Gore, 2006). For normally distributed data, parametric tests were used (Student's t-test, analysis of variance, and Greenhouse-Geisser adjusted degrees of freedom). To examine whether pain assessment rated on the two VAS (i.e., pain intensity, affective distress) varied between groups and their nature, a multivariate analysis of variance (MANOVA) was performed with Group (2) as betweensubject factor and VAS (2) as the within-subject factor. For comparison between correlation coefficients we used a Fisher z-score comparison with a Cohen's q effect size. The Chi-square test was performed for categorical variables. In addition, we calculated the eta squared $\eta^{2}$ and the Cohen's $d^{\prime}$ as measures of the effect size. The effect size was considered small $\left(\eta^{2}=0.01 ; d^{\prime}=0.20 ; q=0.10\right)$, medium $\left(\eta^{2}=0.06 ; d^{\prime}=0.50 ; q=0.30\right)$, or large $\left(\eta^{2}=0.14\right.$; $d^{\prime}=0.80 ; q=0.50$ ) according to Cohen (Cohen, 1988). Relationships between our variables of interest were explored with Pearson or Spearman coefficients. According to Cohen (Cohen, 1988), a correlation between 0.10 and 0.30 represents a small effect, between 0.30 and 0.50 a medium effect, and above 0.50 a large effect.

\section{Results}

\section{Demographic, Socioprofessional, and Psychological Characteristics}

As illustrated in Table 2, no significant differences were found between groups regarding age $(p=.95)$ and education level $(p=.17)$. Past or current experience of chronic pain was not significantly different between the two groups $(p=.22)$.

The CNA participants had lower scores than controls on the empathic concern $\left(p=.002, d^{\prime}=.33\right)$ and personal distress $\left(p=.003, d^{\prime}=.31\right)$ dimensions of the IRI.

The level of burnout measured with the MBI of the CNAs group was globally low to moderate. However, $28 \%$ of the participants presented a high score in at least one of the two studied MBI dimensions.

\section{Pain Assessment}

Distributions of CNAs' pain intensity assessment and empathic reaction scores are presented in Figure 2. The two VAS and the Algoplus scores fell within acceptable normality ranges. Their distributions were wide-spread and characterized by high variability. Similar patterns of distributions were observed in controls. On the whole sample, Algoplus and pain intensity VAS scores were positively related with a small-sized effect $(\mathrm{n}=90, r=.25)$. When exploring the relation between the Algoplus and the VAS within each group, it was found that the correlation did not reach significance in the control group $(r=.06)$ whereas there was a mediumsized effect in the CNAs group $(r=.43)$. There was a significant difference between these two correlation coefficients with a medium-sized effect ( $\mathrm{z}=-1.81, p<.05$, Cohen's $q=.397$ ).

A 2 (Group) $\times 2$ (VAS) MANOVA with pain intensity assessment and empathic reaction measures as dependent variables was performed. These results are illustrated in Figure 3. No significant group-difference was noticed for VAS scores, $\mathrm{F}(1,88)=.89, p=.35$. 
Table 2

Demographic, Socioprofessional, and Psychological Characteristics of Participants

\begin{tabular}{|c|c|c|c|c|}
\hline & Certified Nursing Assistants $(\mathrm{n}=50)$ & Controls $(n=40)$ & Statistics & $p$ \\
\hline \multicolumn{5}{|l|}{ Demographic data } \\
\hline Age, y & $39.30 \pm 11.82$ & $39.48 \pm 16.05$ & $t(88)=.06$ & .95 \\
\hline Years of education & $12.62 \pm 1.32$ & $13.15 \pm 2.1$ & $t(88)=1.38$ & .17 \\
\hline History of chronic pain, yes & $58 \%$ & $45 \%$ & $X^{2}(1)=1.51$ & .22 \\
\hline \multicolumn{5}{|l|}{ Experience, mo } \\
\hline in the present facility & $87.20(1-328)$ & & & \\
\hline in geriatrics & $126.02(1-375)$ & & & \\
\hline \multicolumn{5}{|l|}{ Training and practice } \\
\hline Pain management, yes & $76 \%$ & & & \\
\hline Algoplus use, yes & $74 \%$ & & & \\
\hline \multicolumn{5}{|l|}{ Interpersonal Reactivity Index } \\
\hline Perspective taking & $11.18 \pm 2.94$ & $11.60 \pm 2.72$ & $t(88)=.696$ & .48 \\
\hline Empathic concern & $8.68 \pm 1.88$ & $9.98 \pm 1.90$ & $t(88)=3.233$ & .002 \\
\hline Personal distress & $4.46 \pm 3.03$ & $6.55 \pm 3.51$ & $t(88)=3.027$ & .003 \\
\hline \multicolumn{5}{|l|}{ Maslach Burnout Inventory } \\
\hline Emotional exhaustion & $18.10 \pm 1.58$ & & & \\
\hline Depersonalization & $4.24 \pm .66$ & & & \\
\hline
\end{tabular}

There was no VAS type effect either (i.e., pain intensity, affective distress), $\mathrm{F}(1,88)=3.76, p=.06$. However, the interaction between group and VAS type reached significance with a medium size effect, $\mathrm{F}(1,88)=5.11, p<.05, \eta 2=.06$. The difference between both VAS scores means was significantly greater for the CNAs than for the control group. Finally, no group effect was observed for the Algoplus, $t(88)=1.14, p=.26$.

\section{Pain Assessment Determinants in CNAs Group}

Focusing on the CNAs group, pain intensity VAS scores were moderately and negatively correlated with both experience in geriatrics $(r=-0.44)$ and experience in the present facility $(r=-0.41)$ and the Algoplus scores were moderately and negatively related to experience in geriatrics $(r=-0.30)$. Thus, greater work experience in geriatrics was associated with lower pain ratings with the pain intensity VAS and the Algoplus. No association was found between empathic reaction rated on VAS and demographic, socioprofessional, or psychological characteristics.

Prior pain assessment training in study or professional environment did not have any influence on CNAs pain assessment (all $p$ values $>.05$ ). Nevertheless, on average, CNAs who had already used the Algoplus resulted in lower scores on this tool than those who did not use it $(M=2.81, S E=.164$ versus $M=3.77, S E=.257$; $p=.006, d^{\prime}=.40$ ). Note that both groups (prior use or not) did not differ in terms of age, experience, and scores on the questionnaires.

\section{Discussion}

In this study, we focused on pain assessment behaviors of CNAs working in LTC. Using a standardized experimental paradigm, our first aim was to describe and analyze the pain assessment ratings and empathic reactions of CNAs. We were also interested in exploring the relationships between pain assessment, professional status, personal sociodemographics, and psychological variables in CNAs.

Globally, our results highlighted the interrater variability of pain assessments in CNAs and control participants and showed that both groups did not differ in their assessment behaviors. Nevertheless, CNAs displayed more contrast between the pain intensity they assessed and their empathic reaction. Furthermore, the pain assessment ratings of CNAs were influenced by experience and expertise.

The interrater variability concerned the three dependent variables. Indeed, they were all normally distributed. The pain intensity and affective distress VAS had very wide ranges with scores respectively between 21 to 100 and 5 to 99 , respectively. The Algoplus scores were also widely spread, ranging from 1 to 5 with a mode of 3.

To our knowledge no study has ever focused on assessment variability in such a standardized context, so we did not find any appropriate reference data. Most of the pain assessment research studies were based on interrater comparisons and very few focused on nonverbal or demented patients (Ruben et al., 2018). In the present study, interrater variability may be seen as the consequence of the experimental design. However, disagreements between CNAs about the presence or intensity of pain are relatively frequent (Vitou et al., 2019). Such heterogeneity of evaluation may consequently be met in vivo. Remarkably, our study showed that the use of a more standardized assessment tool such as Algoplus did not entirely prevent interrater variability.

Furthermore, there was no group-effect for pain intensity VAS and Algoplus showing that the professional status provides no specific ability on this practice. These results are in line with a study which compared assessment scores of nurses and laypersons using videos displaying faces of three groups of individuals (young, old, demented) receiving phasic pressure stimulation (Lautenbacher et al., 2013). The authors concluded that the absence of contextual information leaves professional observers without any superior competences in inferring pain in others by reading their facial display. Effectively, in our study, the participants had no idea about the etiology and history of the pain experienced by the older adult woman. This situation can be seen as too experimental to reflect reality. However, in practice, CNAs in LTC are often on the front-line to detect the presence of pain and often care for suffering people without previous contextual or medical information (Snow et al., 2004). Interestingly, Algoplus guidelines require the observer to place himself in the same position asking him to complete the grid independently of any etiological interpretation of the signs but to note only their presence or absence. Nevertheless, our results contrast with other previous studies (Cheng et al., 2007; Decety et al., 2010) which found that health practitioners inferred lower pain intensity compared with non-professionals. In these studies, the stimuli were pictures of painful situations due to a medical procedure and may have elicited less reaction from a healthcare professional than a typical nociceptive pain.

There was no group-effect for the affective distress VAS (empathic reaction), but the significant interaction effect showed that CNAs had a greater difference between the pain intensity assessment and the empathic reaction scores than the control group when they watched the video. This means that even if CNAs 


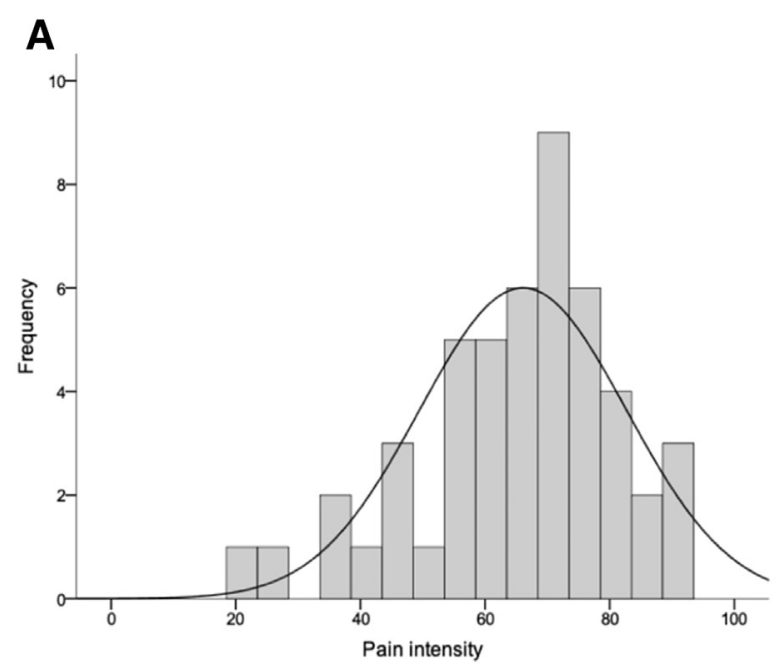

B

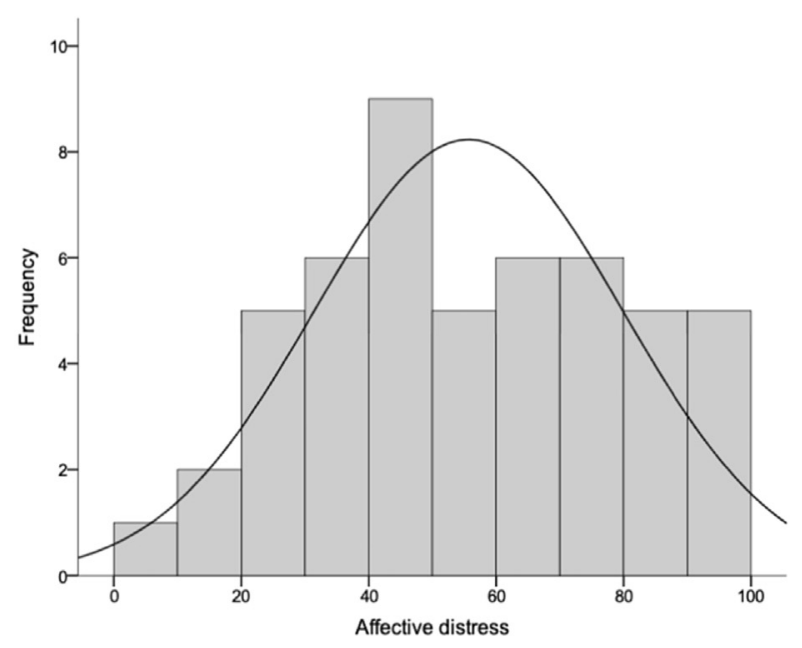

C

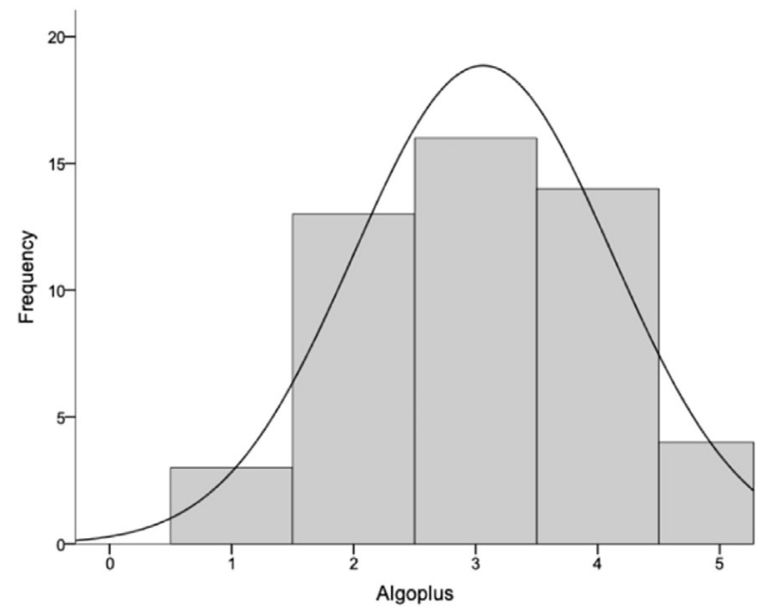

Figure 2. Distribution of pain assessment scores for CNAs on (A) pain intensity VAS, (B) affective distress VAS, and (C) Algoplus. CNA = certified nursing assistant; VAS $=$ visual analog scale.

evaluated the same level of pain in the observed person as the control participants, they were less emotionally affected. Moreover, the CNAs had lower scores than controls on the affective dimensions of the IRI (empathic concern and personal distress) but not on the cognitive one (perspective taking). The most obvious explanation for such results might be the potential levels of stress and burnout of the CNAs which are known to lower their ability and willingness to empathize with others (Chen et al., 2010; Narme, 2018). But in our study, the pain assessment and empathic reaction scores of the CNAs were not related to their level of burnout measured by the MBI.

An alternative argument is provided by neuroimaging studies (Cheng et al., 2007; Decety et al., 2010) which suggested that physicians, compared with matched controls, down-regulate their pain empathy response when faced with others in pain. That means that they may use more cognitive strategies or they may learn to regulate their affective response when detecting or assessing pain (Jackson et al., 2015). On one hand, this phenomenon can be considered as an adaptative skill protecting them from the adverse consequences of personal distress that can cause burnout and freeing up cognitive resources necessary for them to be of assistance (Cheng et al., 2007; Decety et al., 2010). However, these lower empathic dispositions and reactions are thought to reflect a kind of desensitization due to high exposure to suffering in others that leads to a lack of awareness or underestimation (Prkachin et al., 2007).

In our study both explanations may be relevant as the additional analyses of the CNA group showed that pain intensity and Algoplus scores were negatively correlated with experience in geriatrics but not with age, although age and experience were strongly related. This is also in line with several studies which proposed that those with high exposure to suffering in others are more susceptible to underestimation of pain (Grégoire et al., 2016; Prkachin \& Rocha, 2010), and with studies which showed that underestimation of patients' pain is more pronounced in clinicians with more experience (Choinière et al., 1990; Gleichgerrcht \& Decety, 2014).

It is also noteworthy that the two VAS scores were not associated with any dimension of the IRI. This result supports studies that failed to find an association between trait measures of empathy and situational empathic reaction to another's pain (Giummarra et al., 2015; Jackson et al., 2005). Thus, in general situational empathy for pain seems to overlap with empathic trait only partially. Pain assessment may rely on other determinants such as socioprofessional features and/or characteristics of the observed person, e.g., stage of dementia, intimacy.

In this study, pain management training before or during their career course did not influence pain assessment behaviors of the CNAs. This result contrasts with the argument that the lack of specific training of the CNAs is one of the main causes of poor pain management in the LTC (Corbett et al., 2016; Petyaeva et al., 2018; Regan et al., 2015). Contrarily, the CNAs who had already used the Algoplus had lower pain scores with this tool. This is an unexpected result as it means that the more "expert" the CNAs, the less they detect signs that potentially express pain. Due to the experimental conditions, the lack of attention or awareness can hardly be cited. But these findings may suggest that practical experience of this tool would lead either to a more accurate perception of pain cues or to a perverse effect inferring the cause of the observed behaviors. This later assumption may find support in the fact that Algoplus and pain intensity VAS scores showed significant correlation in the CNA group suggesting that their Algoplus rating may have been influenced by their global subjective pain evaluation. If so, the Algoplus guidelines have to be regularly restated to the CNAs in order to ensure the correct use of this tool.

Several limitations and methodologic choices should be taken into consideration. Firstly, the small sample size did not allow us to generalize our results to all CNAs working in LTC and to apply more sophisticated statistical methodologies, e.g., structural equation 


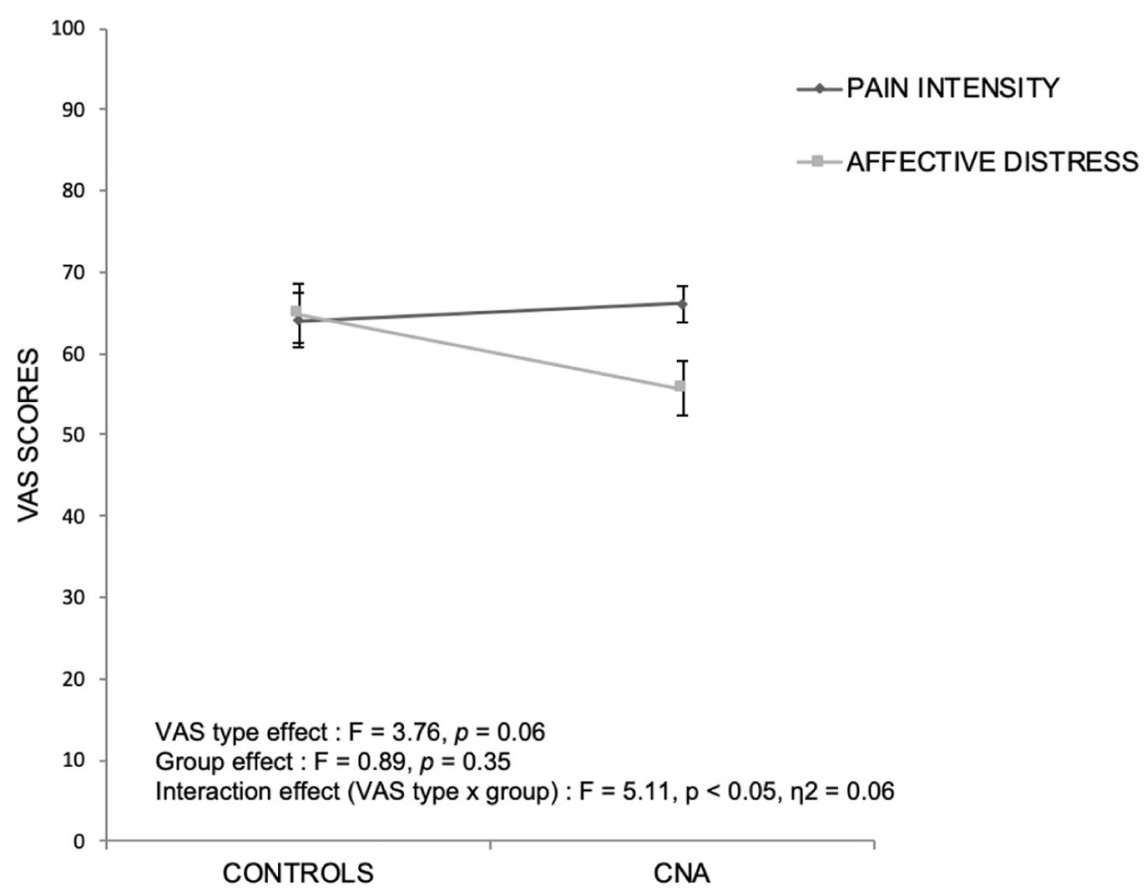

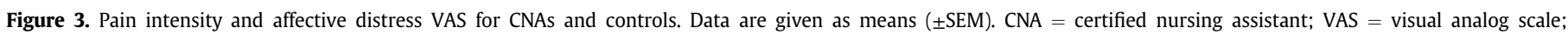
$\mathrm{SEM}=$ standard error of mean.

modelling, to examine the complex relationships between pain assessment behaviors and personal characteristics. Secondly the cross-sectional design of our study prevented us from exploring the causal pathways between pain assessment and the influence of experience. Thirdly, we were aware of the questionable use of pain intensity VAS for proxy-rating in a clinical context, but we deliberately choose to use it for analysis purposes in our experimental context. Indeed, VAS has been used in validation studies of observational pain assessment tools (Hølen et al., 2007; Warden et al., 2003; Zwakhalen et al., 2006). Furthermore, some pain assessment tools include VAS as a global pain intensity rating in their clinical assessment process (Fisher et al., 2002; Villanueva et al., 2003). Finally, VAS is a common measure in research about pain assessment bias (Gleichgerrcht \& Decety, 2014; Prkachin et al., 2007). Fourthly, no study has ever focused on the heterogeneity of pain assessment in such a standardized experimental design making it difficult to compare our results and to conclude that such a phenomenon is common. Fifthly, it would have been interesting to compare CNAs' and registered nurses' pain assessment behaviors but we deliberately chose to focus on the staff that is on the frontline to detect pain during daily care and is scarcely studied. Finally, we favored an experimental design with a video clip which may have dampened the empathic reaction of the observers. We deliberately chose to videotape an actress depicting simulated pain. This choice was based on ethical issues as vulnerable patients with moderate-to-severe dementia are unable to provide fully informed consent. Such method has already been used in scientifically-sound studies: validation of an observational assessment tool for dementia population (Snow et al., 2004), evaluation of the ability of laypeople to use observational pain assessment tools (Ammaturo et al., 2016). Moreover, other studies have shown the inability of healthcare professionals to distinguish genuine and posed expression of pain, even with adequate training (Williams, 2002). Some facial expressions are more frequent in posed pain than in genuine pain, but they are not specific (Galin \& Thorn, 1993). In addition, more intense expressions may also reflect a greater pain experience (Lints-Martindale et al., 2007).

\section{Implications for Nursing}

CNAs play a crucial role in detecting pain in older adult residents with cognitive impairments. But, in order to improve pain management, they have to be aware that using an observational rating tool like Algoplus does not prevent important variability between two raters. This variability may be harmful especially in reassessment situations where treatment decisions have to be evaluated by comparing before and after intervention pain scores. CNAs, like any other healthcare providers, have to keep in mind that surrogate pain assessment always involves subjectivity. Precisely following guidelines and opting for team rating may limit bias. Long-term care facilities management have to recognize the value and support CNAs in order to enhance their abilities and involvement in pain management.

\section{Conclusion}

The results of this study documented that evaluating pain in others is not an exact science. In fact, CNAs in LTC as well as controls showed great interpersonal inconsistency in this practice even with standardized observational tools. CNAs' pain assessment behaviors did not benefit from their professional status but are affected by experience and exposure to pain. Moreover, CNAs displayed lower affect sharing when faced with someone in pain. Such biases may interfere with effective pain management and must be considered. Further studies should explore other determinants of assessment variability of CNAs (e.g., diagnostic and cognitive status of the suffering patient) in order to improve pain detection in LTC residents with moderate to severe cognitive impairment.

\section{Conflicts of Interest}

The authors declare that they have no known competing financial interests or personal relationships that could have appeared to influence the work reported in this paper. 


\section{Acknowledgments}

This research was funded by a CIFRE Device [2017/0559] signed with the Foudation "Fondation Partage et Vie", France, financed by the French Ministry of research and industry implemented by the French national association for research and technology. The funding source had no influence on the conduct and design of the study, neither on the data collection, analysis, the interpretation of the data, the approval of the manuscript or in the decision to submit the article for publication.

\section{Supplementary Data}

Supplementary data related to this article can be found online at https://doi.org/10.1016/j.pmn.2020.12.002.

\section{References}

Ammaturo, D. A., Hadjistavropoulos, T., \& Williams, J. (2017). Pain in dementia: Use of observational pain assessment tools by people who are not health professionals. Pain Medicine, 18(10), 1895-1907.

Björk, S., Juthberg, C., Lindkvist, M., Wimo, A., Sandman, P.-O., Winblad, B., \& Edvardsson, D. (2016). Exploring the prevalence and variance of cognitive impairment, pain, neuropsychiatric symptoms and ADL dependency among persons living in nursing homes; a cross-sectional study. BMC Geriatrics, 16(1), 154.

Blanchard, P., Truchot, D., Albiges-Sauvin, L., Dewas, S., Pointreau, Y., Rodrigues, M., Xhaard, A., Loriot, Y., Giraud, P., Soria, J. C., \& Kantor, G. (2010). Prevalence and causes of burnout amongst oncology residents: A comprehensive nationwide cross-sectional study. European Journal of Cancer, 46(15), 2708-2715.

Braun, S., Rosseel, Y., Kempenaers, C., Loas, G., \& Linkowski, P. (2015). Self-report of empathy: A shortened French adaptation of the Interpersonal Reactivity Index (IRI) using two large Belgian samples. Psychological Reports, 117(3), 735-753.

Cervo, F. A., Bruckenthal, P., Chen, J. J., Bright-Long, L. E., Fields, S., Zhang, G., \& Strongwater, I. (2009). Pain assessment in nursing home residents with dementia: Psychometric properties and clinical utility of the CNA Pain Assessment Tool (CPAT). Journal of the American Medical Directors Association, 10(7), 505-510.

Cervo, F. A., Raggi, R. P., Bright-Long, L. E., Wright, W. K., Rows, G., Torres, A. E., Levy, R. B., \& Komaroff, E. (2007). Use of the Certified Nursing Assistant Pain Assessment Tool (CPAT) in nursing home residents with dementia. American Journal of Alzheimer's Disease \& Other Dementias, 22(2), 112-119.

Chen, Y.-H., Lin, L.-C., \& Watson, R. (2010). Validating nurses' and nursing assistants' report of assessing pain in older people with dementia. Journal of Clinical Nursing, 19(1/2), 42-52.

Cheng, Y., Lin, C.-P., Liu, H.-L., Hsu, Y.-Y., Lim, K.-E., Hung, D., \& Decety, J. (2007) Expertise modulates the perception of pain in others. Current Biology, 17(19), 1708-1713.

Choinière, M., Melzack, R., Girard, N., Rondeau, J., \& Paquin, M.-J. (1990). Comparisons between patients' and nurses' assessment of pain and medication efficacy in severe burn injuries. Pain, 40(2), 143-152.

Cohen, J. (1988). Statistical power analysis for the behavioral sciences (2nd ed.). New York: L. Erlbaum Associates.

Corbett, A., Husebo, Achterberg, W. P., Aarsland, D., Erdal, A., \& Flo, E. (2014). The importance of pain management in older people with dementia. British Medical Bulletin, 111(1), 139-148.

Corbett, A., Husebo, Malcangio, M., Staniland, A., Cohen-Mansfield, J., Aarsland, D., \& Ballard, C. (2012). Assessment and treatment of pain in people with dementia. Nature Reviews Neurology, 8(5), 264-274.

Corbett, A., Nunez, K.-M., Smeaton, E., Testad, I., Thomas, A. J., Closs, S. J., Briggs, M., Clifton, L., Gjestsen, M. T., \& Lawrence, V. (2016). The landscape of pain management in people with dementia living in care homes: A mixed methods study: Pain management in dementia in care homes. International Journal of Geriatric Psychiatry, 31(12), 1354.

Davis, M. H. (1980). A multidimensional approach to individual difference in empathy. JSAS Catalog of Selected Documents in Psychology, 10, 85.

de Souto Barreto, P., Lapeyre-Mestre, M., Vellas, B., \& Rolland, Y. (2013). Potential underuse of analgesics for recognized pain in nursing home residents with dementia: A cross-sectional study. Pain, 154(11), 2427-2431.

De Witt Jansen, B., Brazil, K., Passmore, P., Buchanan, H., Maxwell, D. Mcllfatrick, S. J., Morgan, S. M., Watson, M., \& Parsons, C. (2017). Exploring healthcare assistants' role and experience in pain assessment and management for people with advanced dementia towards the end of life: A qualitative study. BMC Palliative Care, 16(1), 6.

Decety, J., Yang, C.-Y., \& Cheng, Y. (2010). Physicians down-regulate their pain empathy response: An event-related brain potential study. Neuroimage, 50(4), 1676-1682.
Dion, G., \& Tessier, R. (1994). Validation of a French translation of the Maslach Burnout Inventory (MBI). Canadian Journal of Behavioural Science/Revue Canadienne Des Sciences Du Comportement, 26(2), 210-227.

Faul, F., Erdfelder, E., Lang, A.-G., \& Buchner, A. (2007). G*Power 3: A flexible statistical power analysis program for the social, behavioral, and biomedical sciences. Behavior Research Methods, 39(2), 175-191.

Fisher, S. E., Burgio, L. D., Thorn, B. E., Allen-Burge, R., Gerstle, J., Roth, D. L., \& Allen, S. J. (2002). Pain assessment and management in cognitively impaired nursing home residents: Association of certified nursing assistant pain report, Minimum Data Set pain report, and analgesic medication use. Journal of the American Geriatrics Society, 50(1), 152-156.

Gagliese, L., Gauthier, L. R., Narain, N., \& Freedman, T. (2018). Pain, aging and dementia: Towards a biopsychosocial model. Progress in NeuroPsychopharmacology and Biological Psychiatry, 87(Pt B), 207-215.

Galin, K. E., \& Thorn, B. E. (1993). Unmasking pain: Detection of deception in facial expressions. Journal of Social and Clinical Psychology, 12(2), 182-197.

Giummarra, M. J., Fitzgibbon, B. M., Georgiou-Karistianis, N., Beukelman, M., Verdejo-Garcia, A., Blumberg, Z., Chou, M., \& Gibson, S. J. (2015). Affective, sensory and empathic sharing of another's pain: The Empathy for Pain Scale. European Journal of Pain, 19(6), 807-816.

Gleichgerrcht, E., \& Decety, J. (2014). The relationship between different facets of empathy, pain perception and compassion fatigue among physicians. Frontiers in Behavioral Neuroscience, 8, 243.

Goubert, L., Craig, K. D., \& Buysse, A. (2009). Perceiving others in pain: Experimental and clinical evidence on the role of empathy. In J. Decety, \& W. Ickes (Eds.), The Social Neuroscience of Empathy (pp. 153-166). Cambridge, MA: The MIT Press.

Green, A. D., Tripp, D. A., Sullivan, M. J. L., \& Davidson, M. (2009). The relationship between empathy and estimates of observed pain. Pain Medicine, 10(2), 381-392.

Grégoire, M., Coll, M. P., Tremblay, M. P. B., Prkachin, K. M., \& Jackson, P. L. (2016) Repeated exposure to others' pain reduces vicarious pain intensity estimation. European Journal of Pain, 20(10), 1644-1652.

Griffioen, C., Willems, E. G., Husebo, \& Achterberg, W. P. (2017). Prevalence of the use of opioids for treatment of pain in persons with a cognitive impairment compared with cognitively intact persons: A systematic review. Current Alzheimer Research, 14(5), 512-522.

Hadjistavropoulos, T., Herr, K., Prkachin, K. M., Craig, K. D., Gibson, S. J., Lukas, A., \& Smith, J. H. (2014). Pain assessment in elderly adults with dementia. Lancet Neurology, 13(12), 1216-1227.

Helmer, C., Pérès, K., Letenneur, L., Guttiérez-Robledo, L. M., Ramaroson, H., Barberger-Gateau, P., Fabrigoule, C., Orgogozo, J.-M., \& Dartigues, J.-F. (2006). Dementia in subjects aged 75 years or over within the PAQUID cohort: Prevalence and burden by severity. Dementia and Geriatric Cognitive Disorders, 22(1), 87-94.

Hølen, J. C., Saltvedt, I., Fayers, P. M., Hjermstad, M. J., Loge, J. H., \& Kaasa, S. (2007). Doloplus-2, a valid tool for behavioural pain assessment? BMC Geriatrics, 7(1), 29.

Husebo, Achterberg, W., \& Flo, E. (2016). Identifying and managing pain in people with Alzheimer's disease and other types of dementia: A systematic review. CNS Drugs, 30(6), 481-497.

Jackson, P. L., Eugène, F., \& Tremblay, M.-P. B. (2015). Improving empathy in the care of pain patients. AJOB Neuroscience, 6(3), 25-33.

Jackson, P. L., Meltzoff, A. N., \& Decety, J. (2005). How do we perceive the pain of others? A window into the neural processes involved in empathy. Neuroimage, 24(3), 771-779.

Kappesser, J., de Williams, A. C., \& Prkachin, K. M. (2006). Testing two accounts of pain underestimation. Pain, 124(1), 109-116.

Knopp-Sihota, J. A., Dirk, K. L., \& Rachor, G. S. (2019). Factors associated with pain assessment for nursing home residents : A systematic review and meta-synthesis. Journal of the American Medical Directors Association, 20(7), 884-892.

Lautenbacher, S., Niewelt, B. G. \& Kunz, M. (2013). Decoding pain from the facial display of patients with dementia: A comparison of professional and nonprofessional observers. Pain Medicine, 14(4), 469-477.

Lints-Martindale, A. C., Hadjistavropoulos, T., Barber, B., \& Gibson, S. J. (2007). A psychophysical investigation of the facial action coding system as an index of pain variability among older adults with and without Alzheimer's disease. Pain Medicine, 8(8), 678-689.

Martin, E., Doloplus Collective Team, Pereira, B., \& Pickering, G. (2016). Concordance of pain detection using the Doloplus and Algoplus behavioral scales. Journal of the American Geriatrics Society, 64(10), e100-e102.

Mentes, J. C. Teer, J. \& Cadogan, M. P. (2004). The pain experience of cognitively impaired nursing home residents: Perceptions of family members and certified nursing assistants. Pain Management Nursing, 5(3), 118-125.

Narme, P. (2018). Burnout in nursing staff caring for patients with dementia: Role of empathy and impact of empathy-based training program. Gériatrie et Psychologie Neuropsychiatrie du Viellissement, 16(2), 215-222.

Petyaeva, A., Kajander, M., Lawrence, V., Clifton, L., Thomas, A. J., Ballard, C., Leroi, I., Briggs, M., Closs, J., Dening, T., Nunez, K.-M., Testad, I., Romeo, R., Johar, I., \& Corbett, A. (2018). Feasibility of a staff training and support programme to improve pain assessment and management in people with dementia living in care homes: Feasibility of pain management package for care homes. International Journal of Geriatric Psychiatry, 33(1), 221-231.

Prkachin, K. M., \& Rocha, E. M. (2010). High levels of vicarious exposure bias pain judgments. Journal of Pain, 11(9), 904-909. 
Prkachin, K. M., Solomon, P. E., \& Ross, J. (2007). Underestimation of pain by healthcare providers: Towards a model of the process of inferring pain in others. Canadian Journal of Nursing Research, 39(2), 88-106.

Rajkumar, A. P., Ballard, C., Fossey, J., Orrell, M., Moniz-Cook, E., Woods, R. T., Murray, J., Whitaker, R., Stafford, J., Knapp, M., Romeo, R., Woodward-Carlton, B. Khan, Z., Testad, I., \& Corbett, A. (2017). Epidemiology of pain in people with dementia living in care homes: Longitudinal course, prevalence, and treatment implications. Journal of the American Medical Directors Association, 18(5), 453.e1-453.e6.

Rat, P., Bonin-Guillaume, S., Pickering, G., \& Leglise, M.-S. (2014). Algorithme d'évaluation de la douleur chez les patients âgés. Douleurs: Evaluation - Diagnostic - Traitement, 15(2), 52-56.

Rat, P., Jouvel, E., Pickeringl, G., Donnarell, L., Nguyenl, L., Michell, M., CaprizRibièrel, F., Lefebvre-Chapirol, S., Gauquelinl, F., \& Bonin-Guillaumel, S. (2011). Validation of an acute pain-behavior scale for older persons with inability to communicate verbally: Algoplus. European Journal of Pain, 15(2), 198.e1-198.e10.

Regan, A., Colling, J., \& Tapley, M. (2015). Pain management: A fundamental component of dementia care. Nursing Standard, 30(9), 43-50.

Reynolds, K. S., Hanson, L. C., DeVellis, R. F., Henderson, M., \& Steinhauser, K. E. (2008). Disparities in pain management between cognitively intact and cognitively impaired nursing home residents. Journal of Pain and Symptom Management, 35(4), 388-396.

Rostad, H. M., Puts, M. T. E., Cvancarova Småstuen, M., Grov, E. K., Utne, I., \& Halvorsrud, L. (2017). Associations between pain and quality of life in severe dementia: A Norwegian cross-sectional study. Dementia and Geriatric Cognitive Disorders Extra, 7(1), 109-121.

Ruben, M. A., Blanch-Hartigan, D., \& Shipherd, J. C. (2018). To know another's pain: A meta-analysis of caregivers' and healthcare providers' pain assessment accuracy. Annals of Behavioral Medicine, 52(8), 662-685.

Seers, T., Derry, S., Seers, K., \& Moore, R. A. (2018). Professionals underestimate patients' pain: A comprehensive review. Pain, 159(5), 811-818.
Snow, A. L., Weber, J. B., O'Malley, K. J., Cody, M., Beck, C., Bruera, E., Ashton, C., \& Kunik, M. E. (2004). NOPPAIN: A nursing assistant-administered pain assessment instrument for use in dementia. Dementia and Geriatric Cognitive Disorders, 17(3), 240-246.

Tan, E., Jokanovic, N., Koponen, M., Thomas, D., Hilmer, S., \& Bell, J. (2015). Prevalence of analgesic use and pain in people with and without dementia or cognitive impairment in aged care facilities: A systematic review and metaanalysis. Current Clinical Pharmacology, 10(3), 194-203.

Villanueva, M. R. Smith, T. L., Erickson, J. S., Lee, A. C. \& Singer, C. M. (2003). Pain Assessment for the Dementing Elderly (PADE): Reliability and validity of a new measure. Journal of the American Medical Directors Association, 4(1), 1-8.

Vitou, V., Gély-Nargeot, M.-C., Mimoun, N., Million, E., Bayard, S., et al. (2019). Evaluation de la douleur des résidents en Ehpad par des aides-soignantes: une étude en condition écologique. Geriatr Psychol Neuropsychiatr Vieil, 17(4), 423-428.

Warden, V., Hurley, A. C. \& Volicer, L. (2003). Development and Psychometric Evaluation of the Pain Assessment in Advanced Dementia (PAINAD) Scale. Journal of the American Medical Directors Association, 4(1), 9-15.

Weston, R., \& Gore, P. A. (2006). A brief guide to structural equation modeling. The Counseling Psychologist, 34(5), 719-751.

Williams, A. C. de C. (2002). Facial expression of pain: An evolutionary account. Behavioral and Brain Sciences, 25(4), 439-455.

World Medical Association. (2013). WMA declaration of Helsinki: Ethical principles for medical research involving human subjects. www.wma.net/en/ 30publications/10policies/b3/index.html.

Zwakhalen, Docking, R. E., Gnass, I., Sirsch, E., Stewart, C., Allcock, N., \& Schofield, P. (2018). Pain in older adults with dementia: A survey across Europe on current practices, use of assessment tools, guidelines and policies. Der Schmerz, 32(5), 364-373.

Zwakhalen, Hamers, J. P., Abu-Saad, H. H., \& Berger, M. P. (2006). Pain in elderly people with severe dementia: A systematic review of behavioural pain assessment tools. BMC Geriatrics, 6(1), 3. 